\title{
Memory, body and dance: a review of literature
}

\author{
He kitenga kanohi \\ He hokinga whakaaro \\ A face seen, \\ a thought returned
}

Distinguishing dance from movement may be a matter of state of mind, of invested meaning. Dance in English seems easy to define but when we get to phrases like 'the dance of desire' or 'we were lead on a merry dance' and when we try and untangle dance from stance or, in some cases, trance and the dance of an eyebrow or a look we need to carefully describe what is going on.

Maori dance might be translated as kanikani Maori. Kanikani means to move back and forth and it is a general term for dance. Haka, taki, waiata a ringa and various other forms of dance, strut and movement of the hands and other parts of the body while singing are considered below on their own terms as much as possible. Some terms have changed remarkably over time. Haka itself may have, at an earlier time, meant to crouch (Shennan 1975). Kapa means team or group. Kapa Haka, literally a group involved in Haka, has come to be a carry-all term for activities in performance on stage as well 
as displacing the terms of waiata a ringa or action song and the English phrase, 'concert party'.

One difference, traditionally speaking, between kanikani and the other terms is that this term refers to dancing in the light sense as opposed to serious action. Haka was, and is, an invitation and a precursor to war, to actual violence. Haka is not only not quite dance it is not even dance in certain respects. Haka is not quite war.

Memory seems easy to define but, as the discussion below shows, it is not. The same is true of the body in certain respects.

Body in Maori is translated as tinana. We are talking about kiko, flesh and matters corporeal. Memory is something found in the mind or the seat of the emotions, hinengaro, or in the viscera, ate, in the catching of a thought, maumahara, it is a returning of thought, he hokinga whakaaro.

Memory need not happen in the mind and this may be true across cultures. In the Maori case the word used for mind, hinengaro and the word used for heart, ngakau may not, at least not necessarily, be distinguished along the same lines as body and soul, body and mind as set out in the maps of people found elsewhere.

Work by Sharon Mazer and others about Kapa Haka in general and the performer Mika in particular talks about these three things, memory, body and dance, Maori dance in particular with specific reference to Mika and Kapa Haka. We might approach this work through three focal points set out by Mazer (Mazer 2011). These are to do with the proscenium, the idea of memorialisation and desire in the presentation of the body. 
In the discussion of these points raised by Mazer other commentators such as Hamilton (2006), Greenwood and Wilson (2006), Matthews (2004) and Karetu (1993) are also considered. At the same time there is an attempt to consider performance in traditional hui (Salmond 1975, Cleave 2009) and in Kapa Haka (Shennan 1984) in order to provide a context.

The orientations of actor and spectator, audience and performer, real time in the audience space and imagined time on stage, at a point beyond the proscenium, are critical and yet, in a cross cultural situation such as a consideration of Kapa Haka they may be misunderstood

In 'Performing Māori: Kapa Haka on the Stage and on the Ground', published in Popular Entertainment Studies (Vol. 2, Issue 1, pp. 41-53 in 2011) Mazer establishes a link between past and present and pays attention to the significance of history. The audience at Kapa Haka, says Mazer, 'acts back'. At the same time it might be suggested, following but not directly quoting Mazer, that the Kapa Haka performance itself 'acts back' to a past, it works to a script of memorialisation, of breaking up and reformulating the past as a matter of sharp, clear and coherent identity.

Sharon Mazer says that Kapa Haka is a formal performance practice arising at the intersection between ritual theatre and sport. Mazer suggests along the way that Kapa Haka is a signal part of the New Zealand identity, performance and practice.

Mazer also suggests that Kapa Haka performance evokes an idealisation of community as well as a redress for 
colonisation.

Mazer would seem to resist or at least question inclusion;

'Community organisations and civic institutions add karanga (call), haka (dance) and waiata (song) into the start of events such as flower shows, arts festivals and citizenship ceremonies, events that have little to do with Māori culture and with few Māori present. Even at my own university, staff are now regularly invited to waiata practices and expected to be ready to perform in periodic powhiri (ritual welcome) for new staff and to join the singing at the start of European rituals such as orientations and graduations - although most of us, in avoiding these events as a rule, have managed to go a long time without learning our university's waiata as well.'

Without mentioning Marcuse Mazer seems to be talking about his concept of desublimation (Marcuse 2002) where classical music becomes muzak in lifts or something like this idea to talk about the way Kapa Haka is found everywhere in New Zealand including places where there are few Maori. This goes through the essay and in the coda quoted from above Mazer describes how strange she felt at the use of mihi and waiata by non- Maori at a ceremony at her university following an earthquake. This coda is actually a very important piece of writing and says a lot in a few words about identity and its assumption in Aotearoa/New Zealand. The piece is very much based on literal identity. If there were people present who understood Maori, sang in Maori and performed a waiata then, their comprehension notwithstanding, the fact that they were not Maori in a genetic sense of some kind rendered things invalid.

Mazer quotes King (2011);

'Writing from a less explicitly polemic, Pākehā, perspective, 
historian Michael King describes post World War II New Zealand as a confrontation between two competing worldviews, or "myths": for Māori a renewed valuing of whakapapa and turangawaewae as centred on the marae, and for the Pākehā, "the matching myth was that New Zealand had the best race relations in the world, a verdict Pakeha politicians trumpeted at every possible opportunity.'

As with a lot of over the last thirty years literature the duality is creed and Mazer is accepting of it; Maori and Pakeha after King(2011), Belich(2001, 2007) and Salmond (1992) and the publishing tastes of the eighties and nineties, two peoples, two points of reference with perhaps Dalmatians or Chinese gold miners as additional points to the two key identities, Maori and Pakeha.

There is a historicity involved rather like the way Japanese people born after 1945 seem to assume that their history starts then. Mazer uncritically accepts biculturalism, an ideology that was developed post 1975 partly as a reaction to the Hunn Report of 1961 with its 'we are one people' tatou tatou, inclusionist position, partly as a recognition of the significance of the Treaty of Waitangi and partly as a belief that the numbers of people in the country would relate to the Treaty partners, the Euros and the Maori, Maori and Pakeha. The latter assumption has proved to be way off course as the Asian presence in the country surpasses the Maori in the early twenty first century, Treaty settlements cease and things change so that this idiosyncratic and limited sense of historical identity, biculturalism, becomes a curiosity rather than a reality that most people in the country inhabit.

This is a cul de sac, a trap, a colonial trap at that, as two elites congratulate themselves on settlements that make no 
difference. Kapa Haka is used as the doorway to the trap as flower shows are opened with haka. Cheryl Te Waerea Smith (in Murphy ed.1997) talks about 'a cultural cage' and one way to view Mika is that he is trying to break out of several cages, several stereotypes. West (2011) is explicit about the forcing of such stereotypes on Maori adoptees of which Mika is one and at one stage calls for the abolition of the word Maori.

Mazer comes back again and again to confrontation with the Pakeha even though the great bulk of waiata and performance at Matatini is about topics of the day and about tribalism. It is all about competition between iwi and hapu groups with the occasional and often very good urban group. These may not necessarily have a lot to do with Pakeha or confrontation with them although Mazer sems to think so;

'Retrieved from the elements of Māori ritual protocol and traditional performance practices, as part of a larger political movement, Kapa Haka is not in itself "ritual performance" although one might argue that as it stages the revival of Māori language and culture it ritualises Māori resistance to the dominant Pākehā culture.'

Mazer quotes Michael Warner (2002) in talking about a 'social totality' and like Ryan Hartigan (2011 cf Cleave 2013) she talks of a 'counter-public'. Part of this idea is that Kapa Haka, performers and audience are a kind of alternate theatre away from mainstream, Pakeha if you like, theatre taking theatre in a broad reading to include television and other kinds of performance. Kapa Haka offers a theatre for the 'counter nation', a theatre of resistance. In this perspective proscenium has a different kind of weight.

The idea that the kapa Haka festivals and competitions are a way to leave out, to leave behind the non-Maori world rather 
than to constantly refer to it seems to elude Mazer and yet there seems to be a correctness about the idea of memorialisation; inter tribal rivalry is a key part of the historicity of Kapa Haka. People are taken back to a pre-Euro world where tribe and not state is key. This going back to tribe, this realisation of a tribal past, this reconstruction of a primal memory is very important to participants and reflections on the ancestors, nga matua, tupuna and the world they lived in te ao o nehera occur many times.

In an interesting turn of phrase Mazer suggests that when Maori are rehearsing they are simultaneously practising and memorialising being Maori'. As she does this Mazer refers to Diana Taylor's The Archive and the Repertoire: Performing Cultural Memory in the Americas (2003).

There are echoes of earlier theorising here. To take the idea of te ao huruhuri (cf King ed. 1977), the turning world, this is the world of today, the world the audience finds itself in, the world of whirling change. On stage, on te atamira, there is a representation of the ancient world, te ao o nehera, the stone age, te ao kohatu. Memorialisation involves a stepping back into this ancient world, a stepping out of the crazed pace of the world of change.

It might be important to introduce a discussion of ritual and, if you like, ritual connection with respect to memorialisation. To talk of being involved in Kapa Haka is to talk of a world where hui or traditional ceremonial gatherings continue and elide with one another and Kapa Haka rehearsals and performance. There are the Nationals and the regular competitions and there is Matatini. There is the Koroneihana and the Tuhoe Festival and various tribal gatherings where Kapa Haka is involved. There is Waitangi 
Day and The big day at Ratana Pa in the summer when Kapa Haka groups perform along with Brass Bands. The cycle is intensive and extends throughout the year. Taking Mazer's idea of memorialisation happening at rehearsals it could be argued that to be involved in Kapa Haka is to be involved with constant memorialisation in a world of ritual connection.

There is also the memorialisation that occurs in standard kawa, at hui, the mihi mate or salute to the departed for example. And then there are the unveilings, hura kohatu, that take place after a period following a death.

Rawinia Higgins (Higgins 2013) writes about Zepa theory where there is a distinction drawn between Left, the world of formal mihi and Right, the world of everyday speech. Maori, it is suggested, are caught up in a world of mihi where it is difficult to break into a world of everyday talk. Higgins' Left might be compared to Mazers' memorialisation in some ways. People are caught up in a field of memory, the memory of formal process and ritual as well as events and people in time past. This formalisation and, if you like, classicization- my word not Higgins' or Mazer's- is pervasive to the extent that it is difficult to snap out of it and ask someone else to pass the salt.

Then there are the traditional notions, the old saws, of mua and muri where the past is in front and if we were to follow, say, Merata Kawharu (2011) in a recent formulation of this there might be a re-grounding of memorialisation. Kawharu uses the notion of locale anthropologically to consider the marae. The sense of locale here is like the idea of locality as used by geographers in Development Studies and elsewhere (Clarke and Kirkby 1990, Cooke 1990). Mazer does not go near this area but it may be that memorialisation is 
used in locale or locality to give meaning to, say, terms like Kapa Haka. This might be taken back to Kawharu in a suggestion that memorialisation allows an investment of meaning in terms like marae.

The question might also be asked, at what point do our memorialisations start or, for that matter, stop playing tricks on us? Each memorialisation is a selection of an event leaving other events aside by necessity. Some may be reifications. What to leave in and what to leave out?

And it is with the last point above that the argument might link up with great debates from the past such as Levi Strauss v Sartre and hot and cold societies (Levi Strauss, 1966). In a history based, hot society memorialisation might be a way of stepping out of time to celebrate a past event, stepping out of the over heated now to find a moment of agreement with others, a sharing of emotion towards something in the past, something selected out of the run of things. Hot and cold are matters of identity and the selection, celebration and endorsement of ethnic identity found in memorialisation is a cooling off, a touching of base in a highly fluid, at times almost molten context.

There is also the sense of memory as property, my beat, my rhythm, my song, my past, my myth, my memory. Along with this is the idea of the natural, my memory, my native state. Something I can handle at about my speed. With others. My home in our house, our whare. Kapa Haka is a way of finding one's way home.

Conversely there is the situation where something is NOT owned, as in the case described above where Mazer is uncomfortable participating in the waiata of her university. 
Michael Brown (2004) and Michael Goldsmith (2009) approach this in various ways as they discuss native property and nature. I am not sure that they use the perspective of memorialisation in the way that I have, after Mazer or at least with Mazer in mind, or, for that matter the perspectives of other theorists like, say, Foote (1997). Memory does not seem to be in the mix.

The tapu- noa distinction might also be explored here. Is there a tapu aspect to the atamira, the stage, a place where there is not food, there is karakia with the audience in a situation where food is available and things are more relaxed, more profane? Is the entry to a stage like situation, in rehearsal or performance an entry into a state of tapu? This is explored further in a discussion of internal states below.

Mazer talks of aspects of hui in Kapa Haka and speaks of how groups recognise one another. Mazer does not follow the idea of recognition as put forward by Aristotle in catharsis. But there is a very strong element of recognition in hui and Kapa Haka. In the whakaeke or entrance to hui or onto the stage at Kapa Haka one important idea is to see who is coming on;

He kitenga kanohi,

He hokinga whakaaro

A face seen,

a thought returns

Part of the process in whakaeke is to leave space around the people coming on so people can see who is there and allow their memories to be at play before the event starts.

This aspect of memorialisation, where people recognize themselves in the performance of others is not explored by 
Mazer in a direct way but something like this is implied throughout her writing.

If one were to follow Aristotle though, other cathartic aspects of memorialisation than that of recognition would need to be considered. For example to look at the purgative notion of catharsis as well as the recognition notion might be useful. For example when the late John Rangihau (cf Rangihau in King ed 1977) used the saying;

Hokia ki nga maunga

kia purea ai koe

e nga hau o Tawhirimatea

Return to the mountains

that you be purified

by the winds of Tawhirimatea

he was talking about Tuhoe people actually going back to the mountainous terrain of the Urewera but he was also talking metaphorically so that people, especially those people living far away in the cities and without the resources to be returning often were being encouraged to attend hui and Kapa Haka practice. To take this back to Mazer's point about rehearsal and memorialisation John may have been talking about 'touching base'. In a highly colonised situation people have limited opportunities to 'recharge' to 'reconnect' to 'bring their culture back to life', to remember and, perhaps, following Mazer, to memorialise. Kapa Haka rehearsal and performance offers opportunities for this to happen.

Do people attend Kapa Haka as performers or spectators in order to experience catharsis or something like it? To feel clean or whole again?

Is there a release of emotion involved at the moment of recognition as one sees one's past and oneself in it? If so what 
is the nature and scope of the emotion? Is memorialisation something of a rush?

In a recent paper Sophie Bennett suggested that the ihi between performers on stage is critical (2013). Bennett argues that it is difficult to perform with outsiders, people outside Maori or Polynesian cultures. One might go further and suggest a sharing of feelings like ihi, wana and wehi by audience and performers.

This is a field of energy and emotion that is outside of the Western or, for that matter, the Eastern tradition of performance. To speak of a release of emotion in a cathartic moment is, perhaps, to evoke a very different world from that of Aristotle.

In an excellent discussion of the to and fro at Kapa Haka festivals where the audience haka at the stage Mazer suggests that the proscenium is a frame. She discusses utu and talks about the past being on stage and the present in the audience. While the analysis does not go into the kawa and processes of whakautu it does raise some very interesting points.

To return to the whakaeke, the entrance of groups to the stage, the idea is that you are going up. The term is taken from the entrance to a marae where the marae is elevated in the mind even if in actuality the marae concerned is at a lower level than the gate from which a group enters a marae. This gives another take on proscenium, the stage or atamira is a space that is conceptually above as well as in front of the spectator.

Another important consideration in the configuration and conceptualisation of proscenium is the tauparapara that is 
chanted as the whakaeke proceeds. The process of tau or whakatau involves a sense of alighting as in birds from afar, manuhiri, descending and settling. The stage is both ascended and descended upon in the whakaeke with tau.

Performance, so called, in the Maori case is interactive and the distinction between performer and observer switches as tangata whenua make a statement and then manuhiri respond or vice versa. The statement usually includes korero, whaikorero, formal speech, or mihimihi, a round of speech with its own formality, followed by waiata. The latter usually involve more than one person and are often lead by women while the speeches are often made by men. We might talk perhaps of line and culture, culture and line and we might ask how does energy work in Maori ritual and performance?

The lines themselves are important in Kapa Haka. As the form developed under Ngata and Te Puea and others the concert party of the first world war with its fairly rigid formation and the haka which may have always had lines came together so that the way performance works is with women up front for waiata and then the men coming through to the front for haka. This gendering of the front line may be important in thinking about proscenium, the line or space between audience and spectator.

Where are the lines of differentiation and what do they mean? Why line? Why not flow, flow from a point or across a point?

In the wharenui or meeting house the flow of mauri proceeds from the taha iti, the small side of the house with the door closest to it, the side of the locals, to the taha nui, the big side, the side of the visitors, speaker by speaker, song by song. 
These are living spaces as well as performance spaces. Mauri flows from the tahuhu, the spine or ridgepole of the house to the rafters, heke or ribs, to the pou or carvings on the walls of the house. This is the field of energy.

There is not a break in the field like a stage. A stage might wreck the traditional energy field in some ways. There is also an argument of the holistic, the idea that Maori like other indigenous people live in a world without the convention of a stage, a firm or rigid division between spaces.

This goes with the idea that traditional people live in a multiplex world where people take up a point of performance as easily as they take an audience role. This is by contrast to the West where people live, so the theory goes in a simplex world defined by their roles and leave the performance to professionals or 'amateurs' who are treated like professionals.

In the multiplex world the distinction between amateur and professional is not found or if it is there is not the same kind of distinction as in the simplex world. The distinctions between times and worlds on one side or the other of the stage may also be reconsidered in terms of the concepts of simplex and multiplex. The notion of the professional actor is found in the simplex but not, or at least not necessarily, in the multiplex world.

Many things flow. There is a flow of energy, flow of mind, flow of memory. If points of performance, performance spaces, were to be considered in a meeting house, in some areas the tradition of mihimihi inside the house involves the speaker standing with his back close to the wall, close to the pou, close to the energy of the ancestors. To speak of a proscenium between performer-speechmaker and audience in this case is 
difficult.

Along with a proscenium come, perhaps, footlights, a curtain and a prompt and a host of detail. The very idea of a prompt from a set off-stage point seems alien in the meeting house. Prompts may come from anywhere at any time and the distinction, say, between prompting and heckling is mediated or filtered by where things take place. On the marae, the domain of Tumatauenga there is the space for challenge while in the domain of Rongo, inside the house there is the space for supportive dialogue. Prompts, heckles jibes, catcalls, noises off and on are all changed, charged with different meanings according to these contexts. These are very different performance spaces as is the wharekai, the dining hall, sometimes used on the last night of a hui. Sometimes there is a fire outside and that is another space for another kind of interaction and performance.

Coming back to the last night of a hui there are performances sometimes in the wharekai or food hall and these have a 'let it rip' feel to them that is different again to performance on the marae or in the meeting house. To talk about a proscenium in this context might be to stretch an already extended point.

In her discussion of Kapa Haka Mazer quotes Filewod (2002) and suggests that 'the broken line between the precolonial past and the post- colonial present may be connected in performance.'

All of this is something of a prelude to Mazer's next main point. Besides the proscenium and memorialisation Mazer talks about the body and desire as she considers Mika. 
Mazer talks about Mika and not about other male or female performers. Some of what she says about Mika might be applied to other male dancers but there is not a lot on female performers and the desire and sexuality they might have or project.

Like Hamilton Mazer refers to Torgvornick (1990) and takes a bearing from the latter's idea of primitivism. Then Mazer proceeds to an interesting and possibly important comment;

'Much as 1970s feminism began to distinguish between Woman and women, we - whoever we are, and whatever identifications we make for ourselves in the process - might need to consider that the Native is as much a phantasm for natives as for the 'we' in this construct. We then might find looking at these oscillating constructions of Self and Other as ongoing reiterations of the masculine/feminine, nobodied/embodied binaries that perpetually trouble the way we see, and make, performances productive. Every time we touch on the body in this way, in performing an Other, or watching the Other perform, we risk burlesque, and as with burlesque's outré cousins - camp, minstrelsy and kitsch - in inversion we also see the possibility of subversion.'

Mazer takes this argument to a consideration of erotic transactions involving the body, desire and power;

'As he mimics, even parodies, Māori ritual and traditional performance, Mika reveals and revels in the construction of the 'native' in the contemporary cultural imagination. In so doing, he exposes the erotics underlying the performative exchange between performer and audience, wherever we might find it, by reminding us that performances - all performances - are built upon bodies, bodies that invite the look and bodies that do the looking. When these performing bodies are marked 
by gender and/or ethnicity, dominant cultural ideas of gender and ethnicity are potentially destabilised; they become performative, and in their performativity, the ways that desire and power are inevitably intertwined become visible. Burlesque makes the act of looking visible, essential to the erotic exchange between the performer and the spectator, who is never fully in the dark and, as implicated in the act, not necessarily safe in his seat. The more conscious we become of the looking, the more we have the possibility also of seeing the workings of power and desire off-stage.'

How does the loop of desire work and what are its dimensions? Mazer and other women are at the theatre to watch the body of Mika as he, according to Hamilton and Mazer, performs for the non- native men in a homoerotic way. Are the women there to alibi the men, to act as beards for the real loop of desire that the men are in or are the women caught up in that desire and, if so, how? Are there differences in the audience between native men and other men in regard to erotic appeal? What do Maori men get out of all this? And what do Maori women take out of it and what is their gaze?

Regarding the body Mazer says;

'Desire for, in and between native bodies is present, not past and continuously renewed as each group takes the stage.'

Mazer seems to be suggesting that Kapa Haka is a celebration of desire although she does not use these terms.

Importantly Mazer sets out a psychoanalytical perspective on Mika's work and discusses repression. She does not quote Norman O Brown or his book Love's Body (1966) but there is a sense in all of this that Kapa Haka is some kind of realisation of desire, power and body.

Mazer seems to be suggesting that to some people she perceives to be detractors of Kapa Haka like Charles Royal, Kapa Haka is like a burlesque, at least like a pastiche of the 
traditional dance forms. Mazer seems to refute this with;

'Instead of filling the gap created by colonisation, Kapa Haka embodies it. Instead of mourning the imagined precontact native, Kapa Haka celebrates the vitality of the bodies on stage as reciprocated by those in the audience. Desire for, in and between native bodies is present, not past, and it is continuously renewed as each group takes the stage.'

There is then a fascinating treatment of gender looking at colonialisation as the feminization of the native male against a dominant colonial male gaze, one male feminizes another- and then an interpretation of the appearance of women in Kapa Haka as an assertion or a reassertion of traditional gender and power relations.

Mazer ends up by saying that the tourist history of Kapa Haka skirts burlesque, it is 'burlesque-esque'.

But rather like the Freeman- Mead debate over sexuality in Samoa there is a lot being read into desire here. If we take the idea of the feminization of the native male by the colonizing male would it be better to stay with that and suggest that Mika's audience are engaged in a form of racism, a play of subjugation that takes its cues from desire but stands for power? Does a reading that non- native men are seduced and attracted in a homoerotic way to Mika disguise a raw need to dominate and force a change of identity? Desire is a fetching but potentially illusory concept. Is a pursuit of desire as an explanatory notion so much smoke from a fire of power in this case? Mark Hamilton's writing is more on this than Sharon Mazer's.

There are questions of the body and the carnal that might be addressed here. How is the Polynesian body considered in the dance world and in the wider world as well? How far away from stereotypical understanding of the Polynesian dancer is Mika? And, for that matter the analysis of Mika by Mazer and Hamilton? 
As a first step in answering these questions we might follow a LinkedIn discussion on the internet that proceeded from the refusal of a book store in a major American place like New York City to display the cover of a book on belly dancing and went as follows;

Candace Bordelon said;

'....As a modern dancer turned Oriental dancer, I was appalled at the misunderstanding many people had about belly dance. I personally do not like people thinking I am going to take off parts of my $\$ 800$ custom-made costume, nor is it okay to shove dollar bills down my cleavage. Obviously it is well documented that the danse du ventre portrayed (or "misportrayed" here in the U.S.) definitely had its impact on burlesque and striptease, we must remember that these were bastardizations of the dance--the "hootchy-kootchy." The presentation of belly dance in its Arab/Egyptian styling is different. I have been treated poorly, scratched from show lineups, and even "warned" by show producers. For whatever reason, hula dancers can get out there wearing $\mathrm{MUCH}$ less clothing and be above reproach.'

Karen Backstein reponds, "The difference, Candace, has to do with how "Oriental" culture is viewed and the concept of the "harem." There's just a lot of mythology and misinformation there. Pacific culture, by contrast, often is viewed as idyllic and "innocent" in popular perceptions.'

Is all this just a matter of sex in the head? When a bookstore refuses to put a dance picture in the window is that just their problem, their projection of the sexually unsavoury? 
There are several lines of inquiry that are opened up. One is to do with the East, harems and all. One is about the corruption or change of forms in the North American and European markets as danse du ventre became belly dancing. And one is about the Pacific and Polynesia. All lines of enquiry run into and it's all about the body.

The portrayal of the body, female and male has a history and an anthropology in the Pacific. There is the art and anthropology relating to Polynesian women. Gauguin's portraits or, as mentioned above Margaret Mead's ideas about sex (Mead 1930) in Samoa and Freeman's (1999) response to Mead where he challenges what Mead says about Samoan women and sex. There seem to be so many sounds off stage, 'fateful hoaxings', to borrow from Freeman's title in any discussion of Polynesian women and their dancing.

At least Bordelon and Backstein are talking about women and in so doing they may be providing a ballast or an off setting of the emphasis given to men by Hamilton and Mazer in their considerations of Mika.

When Candace Bordelon starts a discussion or continues one by saying;

'For whatever reason, hula dancers can get out there wearing MUCH less clothing and be above reproach.'

And Karen Backstein says; 'Pacific culture, by contrast, often is viewed as idyllic and "innocent" in popular perceptions,'

there is, at first glance at least, a place to begin a discussion. How to come to a consideration of Mika in terms of Backstein's comment? 
Pacific Culture and its dance is outside at least one frame of sexual reference- it is 'innocent' says Backstein. It is 'above reproach' says Bordelon. The critical distinction in the discussion is between the puritanism of the West and the licentiousness of the East. In the East there are drugs and dirty dance forms. There is sex on call in places called harems.

In the West there is puritanism with or without a capital ' $\mathrm{P}$ ' and we can see this in the refusal by Barnes and Noble to put the poster of the pole dancer/ belly dancer in the window. Some pictures of dance might be on display in the window and others might not, some pictures are of women in dance are OK and some are not.

So there is East and West and then there is the Pacific. The latter is a space of innocence, of an idyll, of Paradise where pictures of women dancing are OK as they are outside and beyond East and West.

The West is stuck with the absurdities of Puritanism and its implications for the bodies of women and men.

The Pacific is stuck with the idea that there dance is 'natural' and 'innocent'.

The East is stuck with the atmosphere of the harem.

We, in the middle of this discussion, are stuck with Mazer and Mika and Hamilton and Mika.

The thoughts of Mazer and Hamilton about Mika and about performance of Pacific dance matters, perhaps obliquely but in a salient way in the end, to the points made by Balderon and Backstein. It may be, for example, that as suggested above, the female performance in the Pacific is 
contained in terms of desire and sexuality but Mark Hamilton's thesis (2010) suggests that men engaged in martial arts are in fact involved in body display. This might be taken further to suggest that martial arts are a form, a trap, another kind of cultural cage to come back to Cheryl Te Waerea Smith (1997) from another angle from which performance escapes or within which performance and body display occurs.

Hamilton's work is echoed in other recent writing in New Zealand including Mazer's . For example Emma West's thesis (2012) talks about navigating across and through identities including Maori ones from the point of view of a Maori adoptee in a closed adoption situation. West seems to offer a dance of identity amongst stereotypes, a dance of riposte and manner and display if not a dance of a physical kind. West talks about acting up or acting against stereotype.

At the same time participation in Kapa Haka is a distinct marker of identity in West's thesis.

There is a question of working against the grain or against the form as in a woman doing haka or a man doing hula or in a gay display in a martial arts form. Some dancers are without a fixed form of identity from which to work and Mika might be one of them. The stripper can choose from a wide range of forms, he or she can pretend to be a nun or a priest and play against type. Does the ballet dancer have this range? Can the bona fide hula dancer commence to strip on stage or segue from hula into pole dancing? Why or why not? Why can't Mika do what he does to haka?

In the case of Mika the fluidity of sexual identity involved as well as its points of reference are being played out in a form of dance, Kapa Haka, and its context of dance and cultural 
stereotypes. Point and counterpoint are queried and challenged.

The body-word distinction is important in terms of Mazer's thesis about memorialisation. What exactly is being memorialised? Is it an elemental, visceral feeling expressed in bodily terms rather than something that might be written out? What if performers do not understand the words they are chanting or singing?

There is an equation here, something of an elision at least, of body and language, body and culture.

Do, regarding memorialisation at base, people dance to remember, to remember a primal, visceral sense, a sense of freedom perhaps? And where, exactly, does memory, especially the memory involved in memorialisation take place? In the mind, the heart or in the body? In the viscera or in a kind of richochet across these points? Following Foote's (1997) notion of memorialisation it is a feeling of group belonging that seems most important, sometimes even more important than the thing remembered.

People in the Kapa Haka generations, since Apirana Ngata and Te Puea began to encourage astion songs in the 1920s did not, at least not always, learn the reo by sitting at home and writing letters, they gathered in groups and got to know their language by singing it, chanting it and writing songs and chants for their groups to take on tour where they would hear others who had been through similar processes.

This takes things back to the beginning of waiata a ringa concert parties in that Sir Apirana Ngata and Princess Te Puea 
and others involved after World War One saw waiata a ringa as a way of retaining the Maori language, te reo Maori. There is no question that this is still a strong belief amongst adherents and participants in Kapa Haka today. Is it true that participation in Kapa Haka, more than or as well as as other methods helps people learn the Maori language? Does Kapa Haka offer an apparently easy way to learn? Does it help with conversational Maori? Or do people just learn a set of commands and some formal speechmaking as well as the waiata and haka involved?

Mika and Torotoro performed in this context of a fusion of body, dance, group activity, language and culture And as part of this there are issues of vocabulary and Hamilton picks up on this;

'In his monograph Haka! The Dance of a Noble People Tìmoti Kāretu (quoting haka exponents Ngāpō Wehi and Kīngi İhaka) states:

Without the word there is no haka and this is the one aspect of contemporary haka that needs attention [...] The language, which is fundamental to the issue, is becoming peripheral while the actions and movements, the peripheral elements, are becoming the prime focus' (Kāretu 1993:83-4).

Kāretu's proposition is somewhat challenged by Nathan Mathews article "The Physicality of Maori Message Transmission," which offers a detailed examination of the extensive movement vocabulary of haka and its expressive value (Mathews 2003). He argues that physicality should be attributed greater importance in the analysis of how haka communicates.'

Hamilton 2012: 86

Simon Napier Bell (2002) argues that music with a beat is 
an opiate and the rhythmic beat of kapa haka and the pounding of the floor to the command of Waewae takahia! or 'Stamp your feet!'. may have a mesmeric effect. While there are speech competitions and debates at ahurei the predominance of waiata a ringa and haka is striking.

There are also memories from the womb where mothers danced, swayed and sang to a beat.

Is haka like pukana, the rolling of the eyes and protrusion of the tongue, an out of mind experience and does this suggestion go with the idea of the beat as an opiate? Is this experience out of body, out of mind carne vale, goodbye flesh, a transport of desire? Is a word-body distinction relevant in an ecstatic moment such as that found in pukana?

Is theatre or dance or Kapa Haka a matter of words or bodies, or are they always about the latter and sometimes about both?

Another issue with words is literacy. There has been a warp to the traditional through literacy (Moon 2000, Cleave 2009). The conventional wisdom is that Kapa Haka is part of an oral tradition although this is debatable in some ways.

Is an emphasis on words a Pakeha way to go?

Does literacy, especially if words are printed out, freeze things?

Is Mazer or any other writer about Kapa Haka including the present author about words or bodies or more of one than another? Are writers about dance giving a field of words to a set of actions that actually stand alone?

If we look at Kapa Haka as a twentieth century 
development beginning with concert parties in the 1920s we might ask what is the role of the haka and waiata in traditional Maori performance. What came before? To do that we might look at whaikorero and read, say, Mahuta (1974), Salmond (1977), Cleave (2009) et alia.

The kinds of performance involved might be considered. For example there is a type of tapu involved in whaikorero and the use of a waiata at the end of the speech is a form of whakanoa, of making noa or every day, profane. Waiata including waiata a ringa was rephrased in the twentieth century to be a standalone kind of performance outside of this tapu-noa distinction. Having said that whaikorero is part of kapa haka, albeit limited.

Have writers and commentators on Kapa Haka and, for that matter other forms of dance missed the point? Is this all about a visceral gratification, a basic bodily experience where meanings simply occur, almost at random, as dance proceeds?

Would we be better to consider haka as an internal state rather than something that happens on a stage? This might take us back to haka as crouch, as attitude. Would we be better to consider a set of internal states as with a tapu state in whaikorero, a noa state in waiata and an out of body state in pukana?

That might leave us considering all this as articulations of internal states. For some reason the literature on Maori society and culture generally and specifically about dance and ritual does not go there. Analysis, it would seem, proceeds from the external.

How then to consider theatre as a matter of proscenium and stage and audience, or memorialisation and its various 
qualities?

With respect to internal states and this would include, possibly, mood, can we speak of these referring to the satisfaction of needs?

What are the bodies, female and male, carrying already? Mark Hamilton says;

'In her 2001 journal article "Bodies, Revolutions, and Magic: Cultural Nationalism and Racial Fetishism" Josephine Lee adapts Butler's theorising of gender as the legacy of sedimented acts to explore race as a comparable performative construct. Lee says:

"The particular ways in which we perceive, interpret, and value racial difference in the United States today can be understood as a kind of 'performance' that takes its significance from not one but, in fact, many layers of social meaning, that history has deposited on bodies (Lee 2001:72)."

Hamilton 2012: 40

Is Mika 'acting up' or 'acting back' to history, with or without a capital ' $\mathrm{H}$ '. The most striking feature of his performance is with regard to sexual stereotypes handed down, as it were, through generations of Kapa Haka. In the performance of females is there more titillation, shorter skirts, more inviting make up and that sort of thing than there used to be? The answer to these would seem to be in the negative. The skirts are the same; there is not a movement by female Kapa Haka performers into pole dancing postures or anything like that. But there has been with males, one in particular and that is Mika.

In, for example, 'Hongi' Torotoro shifts back and forth between martial movements that prevent a challenge to their 
audience and dance movements that invite and welcome their gaze. Hamilton sees this as both confrontational and inviting;

'The dancers' minimal clothing might also be seen to contribute to the confrontational-inviting tone of their performance, for it displays their well-toned bodies in a way that might be seen underline their martial readiness but also to offer a potentially erotic spectacle. What is more, when a difference of ethnicity, or race, distinguishes the companies from their audiences this might be seen to contribute additional tensions and ambiguities to the bodily spectacle created in their martial dance theatre.'

Hamilton 2012:13

How do we explain Mika? Mazer talks about Mika in terms of burlesque. Is it possible to talk about Mika in terms of Bhapha's third space? Janinka Greenwood (1999, Greenwood and Wilson, 2006) suggests the use of this model in a general consideration of Maori theatre. Mika in Bhapha's terms would be a third space, neither traditional Maori nor Pakeha.

Another way to look at Mika is in terms of Mardi Gras and to the present author this approach is promising but not appearing so far in the literature. The Gay Mardi Gras of Sydney, the Hero parades in Auckland and the tradition of Mardi Gras in, say, Rio or New Orleans all seem to be places where we might find Mika. The fact that there is not a tradition of Mardi Gras, except, say, for the odd parade, in Aotearoa need not rule this out as a way of considering Mika and with his involvement in the Aroha Mardi Gras recently there may be even more of a case to be made here.

In concluding, there are several points made in the discussion of a subject, Mika, as he has been considered by Sharon Mazer and Mark Hamilton. We are not simply talking 
about one performer but rather about a development that others such as the other performers in Torotoro and others share. Mika forms the centre of attention, the point taken for consideration by these writers.

Mika has broken the frames, snapped us out of sclerosis and made us think again about Maori dance. Perhaps he has jogged our memories with his body and we are trying to get back to something now...

Does Mika offer a new way of remembering? Mazer does not directly suggest this in her discussion of memorialisation but it may be so.

Has Mika altered the way we think of the Kapa Haka stage and the proscenium? Possibly. He has brought the club, the intimate performance atmosphere. With others he has helped bring the boogie to the haka.

Has Mika made us think again about the Maori body? Yes.

Are we simply talking about crossover? Like Howard Morrison or John Rowles in popular music. Sir Howard and his quartet took an act from Ohinemutu, an act entertaining tourists, to an international stage. Has Mika simply moved from the clubs of Kings Cross and Karangahape Road to Edinburgh?

Another example of cross over is the film the piano where Baines, the Pakeha with his semi tattooed face lives on the margins of Maori and Pakeha society and Ada moves over to be with him from the world of the piano. The present author has explored these criss crossings and the matter of the grotesque in discussions of the film and book, the piano 
(Cleave 1997). The play within the film where local Maori show no regard for a proscenium dividing the meaning of a shadow play and themselves may also apply to Mazer's arguments about proscenium.

Whatever, there seems to be a shifting out of shape, a shape shifting going on.

Putting Mika as subject aside and considering three of the points that Mazer raises to do with the proscenium, memorialisation and the presentation of desire through the body it may be that the way we think about Maori dance including but not limited to Kapa Haka might need to be reconsidered.

Mazer well may have opened the door to important new considerations in her use of the term memorialisation and, as pointed out above, any such new considerations might be cross referenced to other scholars such as Foote and to other arguments. Dance, Maori dance has a kind of weight that had previously not been assayed, a density of meaning as described variously above under the heading of memorialisation, taken further and into different dimensions perhaps than intended by Mazer.

Similarly Mazer's use of the term proscenium has been reworked and worried above. The call above to consider Maori performance in terms of the energy flow or energy field of traditional hui especially that held inside the house being one example of this.

Desire and the body have been given a treatment above but the work of Mazer and Hamilton, Matthews and Karetu 
locally as well as Backstein Bordelon, Filewod and Lee internationally give us a range of excellent references for consideration.

No question that Mazer points to several roads that require careful walking. No question as well that a number of terms in Maori dance starting with the term haka itself might well be looked at again. After this the questions start to fly around words like memory, body and dance. 


\section{Bibliography}

Barba, Eugenio. 1995. The Paper Canoe: A Guide to Theatre Anthropology. London; New York: Routledge

Belich, James 2007 Making Peoples: A History of the New Zealanders from Polynesian Settlement to the End of the Nineteenth Century. Penguin, 2007.

2001 Paradise Reforged: A History of the New Zealanders from the 1880s to the Year 2000. University of Hawai'i Press

Bennett, Sophie 2013 at Kowhiti Atarau Unpublished Paper

Bhabha, Homi (1990a) "The Third Space" in Rutherford, Jonathan (ed) Identity: Community, Culture, Difference, Lawrence and Wishart, London, p207-221

Brown, Michael F 2004 Who owns Native Culture, Harvard University Press

Brown, Norman O 1966 Love's Body, University of California Press

Buchli, V. \& Lucas, G. 2001. Between remembering and forgetting. In Buchli, V. \&Lucas, G. (eds.). Archaeologies of the contemporary past 79-83. Abingdon:Routledge.

Čehajić, S. \& Brown, R 2010. Silencing the past: effects of intergroup contact on acknowledgement of in-group responsibility.

Social Psychological and Personality Science

1(2): 190-196.

Clarke, S. E., \& Kirby, A. (1990). In Search of the Corpse the Mysterious Case of Local-Politics. Urban Affairs Review, 25(3), 389412 .

Cleave, P 1997 From the Depot Takirua, Campus Press

Cleave, Peter 2000 Ed. The Changing Field, Campus Press 
Cleave Peter, 2009 Seen, heard, written, read, Te Kaharoa, vol. 2

Cleave, Peter 2009 Rangahau pae iti kahurangi, Research in a Small World of Light and Shade, Campus Press

Cleave, Peter 2012 Theories of Art, Performance and Society in Aotearoa, Campus Press

Cooke, P. (1990). Locality, Structure, and Agency: A Theoretical Analysis. Cultural Anthropology(1), 3. doi: 10.2307/656501

Dyer, Richard. 1992. Don't Look Now: The Male Pin-Up. In The Sexual Subject: A Screen Reader in Sexuality, edited by M. Merck. London; New York: Routledge.

Edkins, J. 2003. Trauma and the memory of politics Cambridge: Cambridge UniversityPress.

Fengqi, Q. 2009. Let the dead be remembered: interpretation of the Nanjing massacre memorial. In Logan, W. \& Reeves, K. (eds.). Places of pain and shame: dealing with 'difficult' heritage 17-33 London: Routledge.

Filewod, "Modernism and Genocide: Citing Postcolonial AgitDlics," Public Culture 14:1 (2002): 88.

Foote, K. 1997 Shadowed ground: America's landscapes of violence and tragedy. Austin: University of Texas Press

Foster, Susan Leigh. 2001. Closets Full of Dances: Modern Dance's Performance of Masculinity and Sexuality. In Dancing Desires: Choreographing Sexualities on and off the Stage, edited by J. Desmond. Madison: University of Wisconsin Press.

Freeman, Derek (1999). The Fateful Hoaxing of Margaret Mead: A Historical Analysis of Her Samoan Research, Boulder, Colorado: Westview Press 
Goldsmith, M 200 Who Owns Native Nature? Discourses of Rights to Land, Culture, and Knowledge in New Zealand International Journal of Cultural Property. Vol 18, Special Issue 03 August

Greenwood, Janinka and Wilson, Arnold Manaaki 2006 Te Mauri Pakeaka, A Journey into the Third Space, Auckland University Press

Hamilton, Mark James 2010 Martial Dance Theatre: A Comparative Study of Torotoro Urban Māori Dance Crew (New Zealand) \& Samudra Performing Arts (India)

A thesis submitted in partial fulfilment of the requirements for the Degree of Doctor of Philosophy in Theatre and Film Studies in the University of Canterbury

Hartigan, Ryan, 2011 Embarrassing Time, Performing Disunity Rugby, the haka, and Aotearoa-New Zealand in the United Kingdom in Performance Research (Vol 16 No 2 37:44).

Higgins Rawinia 2013 Zepa unpublished paper given at a $\mathrm{Te}$ Mangai Paho Hui, Rangitaane Pa

Karetu, Timoti 1993 Haka! The dance of a noble people, Auckland: Reed

Kawharu, Merata 2010 Environment as a marae locale, in Selby Moore and Mulholland Ed.

King, Michael (1975), Te Ao Hurihuri, Hicks Smith and Sons Ltd, New Zealand

King, Michael (1977) Te Puea, Hodder \& Stoughton, New Zealand

King, Michael (ed) (1978) Tihe Maori Ora: Aspects of Maoritanga, Methuen, NewZealand

King, Michael (1985) Being Pakeha, Hodder \& Stoughton, New Zealand 
King, Michael (ed) (1991) Pakeha: The Quest for Identity in New Zealand, Penguin Books, Auckland

King Michael 2011 The Penguin History of New Zealand, Penguin

Levi Strauss, C 1966 The Savage Mind, University of Chicago Press

Mahuta, Robert 1974 Whaikoorero, a study of formal Maori speech, Master of Arts thesis, University of Auckland

Marcuse Herbert 2002, One Dimensional Man, London pp75-8

Matthews, Nathan 2004, The Physicality of Māori Message Transmission- Ko te tinana, he waka tuku kōrero Junctures 3 December

Mazer, Sharon 2011, Performing Māori: Kapa Haka on the Stage and on the Ground, published in Popular Entertainment Studies (Vol. 2, Issue 1, pp. 41-53)

Mazer, Sharon (forthcoming, October 2011). "Performance: Ethnographer/Tourist/Cannibal," Australasian Drama Studies

2007 "Acting Back," (paper presented at PSI 13, New York University, November

2010 "You Talkin' to Me? Eavesdropping on the Conversation at Te Matatini Māori Performing Arts Festival," (paper presented at PSI16, York University and Ontario College of Design, June 2010).

Mead, Margaret, 1930 Coming of Age in Samoa, William Morrow and Company

Moon, P 2000 Maori transition to a literate society in the nineteenth century (In Cleave, Ed 2000)

Murray, David 2000, "Haka Fracas? The Dialectics of Identity in 
Discussions of a Contemporary Maori Dance," The Australian Journal of Anthropology 11:3: 345-357

Napier-Bell, Simon 2002 Black Vinyl White Powder, Ebury Press

Papesch, Te Rita 2009 "Kapa Haka: From the New Zealand Postgraduate Conference, Victoria University, Wellington, 20-21 November

Royal, Te Ahukaramū Charles 1998 PhD thesis, "Te Whare Tapere: Towards a New Model for Māori Performing Arts" (Dept. of Theatre and Film, Victoria University

Salmond, Anne, 1985 Hui: A study of Mãori Ceremonial Gatherings, Auckland: Reed. Methven

Salmond, Anne 1992 Two Worlds: First Meetings Between Maori and Europeans, 1642-1772 University of Hawaii Press

Selby, Rachel, Moore, Pataka, Mulholland, Malcolm, 2010 Maori and the Environment: Kaitiaki, Huia Press

Shennan, Jennifer 1984 The Maori action song: waiata a ringa, waiata kori, no whea tenei ahua hou?

NZCER

Smith, Cheryl Te Waerea in Murphy, T. ed, (1997). Te Pumaomao An awakening to rediscover and celebrate Mana

Mäori. Te Whare Wananga o Awanuiarangi

Taylor, Diana, 2003 The Archive and the Repertoire: Performing Cultural Memory in the(Durham, NC: Duke UP

Torgovnick, Marianna 1990 Gone Primitive: Savage Intellects, Modern Lives University of Chicago Press

Warner, Michael (2002) Publics and Counterpublics, 
New York: Zone Books

West, Emma 2012 Manu is my Homegirl:

Navigating the Ethnic Identity of the Mãori Adoptee, A thesis submitted to

Auckland University of Technology

in fulfilment of the requirements for the degree

of Master of Philosophy (MPhil) Faculty of Te Ara Poutama

Internet citations

Linked In Dance History

http://www.academia.edu/2043995/How_Not_to_Remember_War

_Crimes_Memorialisation_and_Reconciliation_in_Bosnia-Herzegovina 